\title{
Synthesis of PDLA-co-TEHA Copolymer Patches for Skin Injury Treatment ${ }^{\dagger}$
}

\author{
Ioanna Koumentakou 1,*, Evi Christodoulou ${ }^{2}$, Dimitrios Bikiaris ${ }^{3}$ and Anna Michopoulou ${ }^{4}$ \\ 1 Ioanna Koumentakou, Laboratory of Organic Chemical Technology, Department of Chemistry, Aristotle \\ University of Thessaloniki, GR-54124, Thessaloniki, Greece, iwanna.koumentakou@gmail.com \\ 2 Evi Christodoulou, Laboratory of Organic Chemical Technology, Department of Chemistry, Aristotle \\ University of Thessaloniki, GR-54124, Thessaloniki, Greece, evicius@gmail.com \\ 3 Dimitrios Bikiaris, Laboratory of Organic Chemical Technology, Department of Chemistry, Aristotle \\ University of Thessaloniki, GR-54124, Thessaloniki, Greece, dbic@chem.auth.gr \\ 4 Anna Michopoulou, Biohellenika Biotechnology Company, Leoforos Georgikis Scholis 65, GR 555 35, \\ Thessaloniki, Greece, annamichop@yahoo.gr \\ * Correspondence: Ioanna Koumentakou iwanna.koumentakou@gmail.com \\ + Presented at the First International Conference on “Green" Polymer Materials 2020, 5-25 November 2020; \\ Available online: https://cgpm2020.sciforum.net/.
}

Published: 4 November 2020

\begin{abstract}
Skin injuries are encountered by millions of patients globally. They are caused by burns, chronic ulcers of different causes, infections, cancer surgery, and other diseases, and require effective treatment to prevent morbidity or mortality. Various patches, with a plethora of properties such as to restore the function of the skin after damage and to facilitate wound healing have been created. This work concerns the production of a patch with prolonged action based on poly (d-lactic acid) (PDLA) with thioether-containing $\omega$-hydroxyacid (TEHA). PLA is an aliphatic polyester derived from lactic acid, that stands out in a wide range of medical applications, because of its biocompatibility and renewability, and excellent mechanical, thermal and processing properties. It is available at a low cost compared to other common biodegradable polymeric biomaterials. However, the in vivo hydrolysis rate of PLA is very slow. For this reason, block copolymers of TEHA and PDLA (TEHA-co-PDLA) were prepared in various ratios in order to slowly release active substances topically on the skin. The physicochemical properties of the prepared copolymer were examined with FTIR, DSC and XRD. From 1H NMR and FTIR the successful synthesis of the materials was confirmed. XRD measurements revealed the amorphous form of TEHA-co-PDLA copolymers. DSC was used to be studied the thermal properties of the materials.
\end{abstract}

Keywords: copolymers; poly(d-lactic acid) ; skin tissue engineering

\section{Introduction}

Skin is the largest organ of the body and it is critical to the survival of the organism because it acts as a barrier to the external environment [1]. Once the skin suffers serious defects, the created wound will severely affect people's life and health [2]. Skin injuries are encountered by millions of patients globally. They are caused by burns, chronic ulcers of different causes, infections, cancer surgery and other diseases, and require effective treatment to prevent morbidity or mortality. The restoration of skin's integrity following an injury remains an important consideration in medical practice [3]. Various patches, with different properties have been created in order to restore the function of the skin after damage and to facilitate wound healing [4].

Thus, significant efforts have been dedicated towards developing synthesis of materials that can be used as a scaffold for skin treatment [5]. Dressings like films are used to treat wounds directly, 
and can also be used to deliver drugs, such as antimicrobials and anti-inflammatories directly to the wound site, to tackle infections and / or pain [3]. An ideal wound dressing should be non-allergenic and non-toxic, it should protect the wound against microbial organisms, absorb wound exudates, and it should facilitate the application around difficult areas such as joints (knees, ankles and elbows) owing their flexible mechanical behaviour [6].

In this work, a thioether-containing $\omega$-hydroxyacid (TEHA) was synthesized, via the UVinduced free-radical thiol-ene reaction. The resulting $\alpha, \omega$-bisfunctional fatty acid was used as a renewable monomer for the development of a fully biobased and biocompatible polyester based on polylactic acid (PLA).

The polyester and copolyesters of several hydroxy acids have been used widely during the past 20 years. Many aliphatic polyesters possess desirable properties, and among the numerous polyesters studies so far, PLA has proven to be the most attractive and useful class of biodegradable polyesters [7]. Many investigations have been carried out on PLA and its copolymers on biomedical applications for wound treatment, because of its mechanical properties, degradability, transparency and ecofriendly nature. As lactic acid has two stereo-isomers, L-lactic acid and D-lactic acid, its polymer product can be synthesized in many forms such as poly(L-lactic acid) PLLA, poly(D-lactic acid) PDLA or racemic products [8].

In this work, the hydrophobic copolymer PDLA-TEHA was prepared, which consists of biocompatible PDLA copolymerized with TEHA. This copolymer could be used for the preparation of a long-acting patch of PDLA with improved biocompatibility and slow release of release bioactive molecules over a period of up to 2 months.

\section{Experiments}

\subsection{Synthesis of Thioether-Containing $\omega$-Hydroxyacid}

To synthesize fatty acid derived monomer (TEHA), a method described in the literature was followed [9]. In brief, 10-undecenoic acid $(15 \mathrm{~g}, 81 \mathrm{mmol})$ and 2-mercaptoethanol $(6.36 \mathrm{~g}, 81 \mathrm{mmol})$ was irradiated in dichloromethane solution at $\lambda=365 \mathrm{~nm}$ in the presence of DMPA (2\% TEHA/initiator molar ratio) as photoinitiator (Scheme 1). The completion of the reaction was confirmed after $60 \mathrm{~min}$ by the completely disappearance of $\mathrm{C}=\mathrm{C}$ double bonds from Proton nuclear magnetic resonance (1H-NMR). The thioether containing $\omega$-hydroxyacid was obtained quickly. $1 \mathrm{H}$ $\mathrm{NMR}\left(\mathrm{CDCl}_{3}, \mathrm{~d}, \mathrm{ppm}\right): 3.72\left(\mathrm{t}, 2 \mathrm{H},-\mathrm{CH}_{2}-\mathrm{OH}\right), 2.73\left(\mathrm{t}, 2 \mathrm{H},-\mathrm{CH}_{2}-\mathrm{S}-\right), 2.51\left(\mathrm{~m}, 2 \mathrm{H},-\mathrm{CH}_{2}-\mathrm{S}-\right), 2.34$ (t, $\left.2 \mathrm{H},-\mathrm{CH}_{2}-\mathrm{CO}\right), 1.69-1.27\left(\mathrm{~m}, 16 \mathrm{H},-\mathrm{CH}_{2}-\right)$.

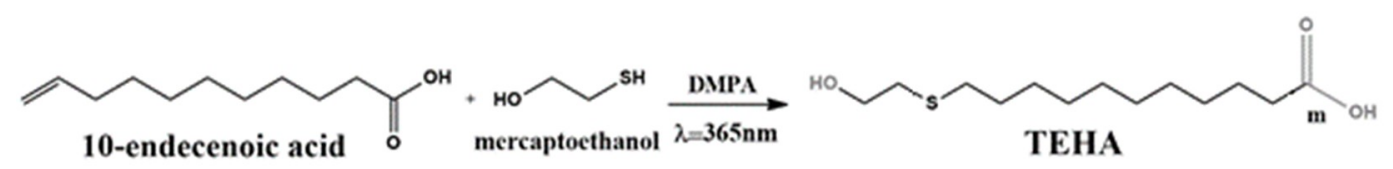

Scheme 1. UV-irradiated synthesis of TEHA monomer.

\subsection{Synthesis of polylactide (PDLA) by ring opening polymerization of lactide}

This process, starting from lactic acid involves three distinct stages: polycondensation, obtaining lactide and ring-opening polymerization [10]. Before using, $10 \mathrm{~g}$ D,L-lactide was freezed for $3 \mathrm{~h}$ and then freeze-dried for $12 \mathrm{~h}$, to remove the entire amount of water from its mass. In the first step, PDLA was synthesized by bulk polymerization of D-lactide in nitrogen atmosphere at $160^{\circ} \mathrm{C}$ for $1 \mathrm{~h}$ and $\mathrm{Sn}(\mathrm{Oct}) 2$ was used as a catalyst. In the second step, the system was heated to $180{ }^{\circ} \mathrm{C}$ under vacuum for $5 \mathrm{~min}$ [8]. The synthesis scheme of PDLA by ring opening polymerization is shown in Scheme 2. 


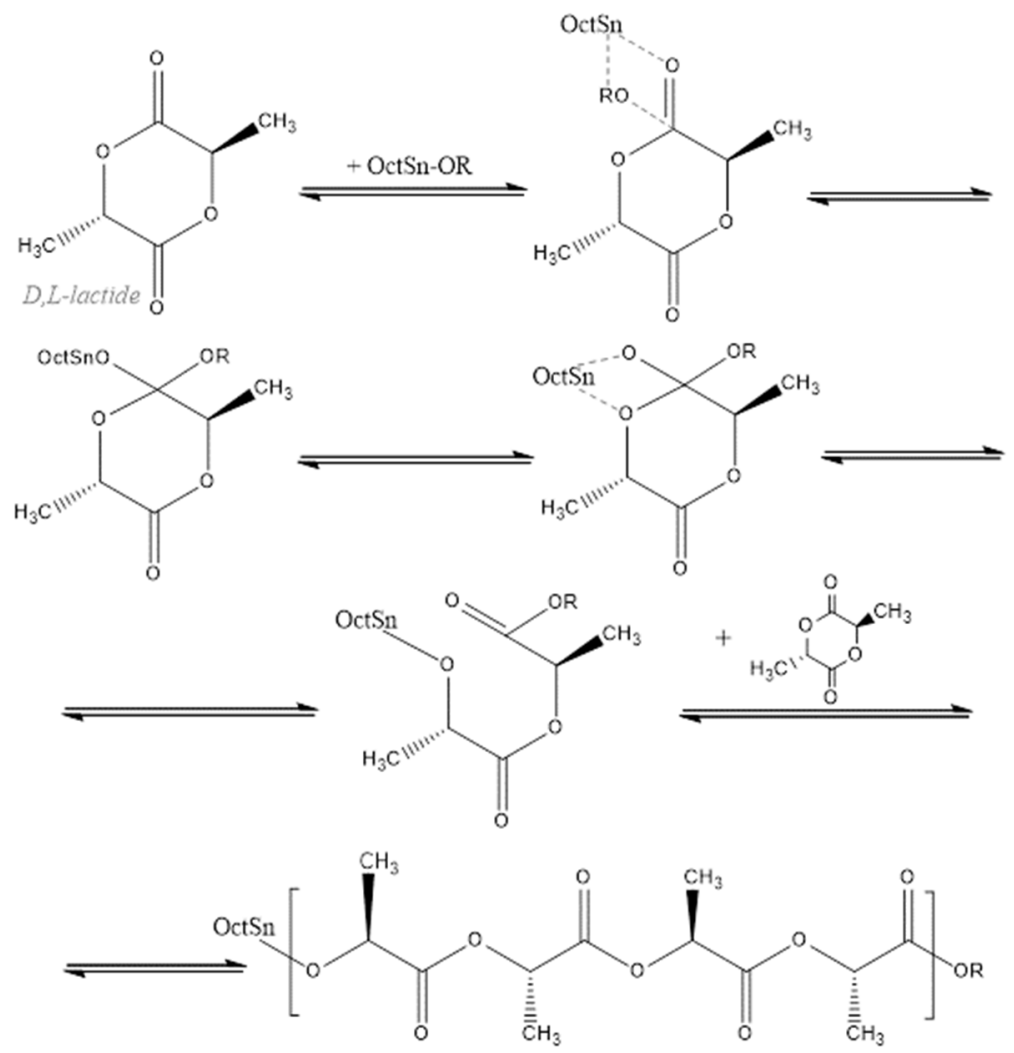

Scheme 2. Ring opening polymerization (ROP) of D,L-lactide.

\subsection{Synthesis of TEHA-CO-PDLA}

TEHA-co-PDLLA copolymers were synthesized by a lactide ring opening mechanism in the curing device, as shown in Scheme 3. The required amount of lactide (D, L-lactide) and hydroxy acid (TEHA) with different molecular ratios, as shown in Table 1, as well as the required amount of catalyst $\mathrm{Sn}(\mathrm{Oct}) 2$, in a ratio of $1 \mathrm{wt} \%$ of mass of the lactide, were introduced into the glass reactor and air was removed from the system and purged with dry nitrogen three times. Esterification was carried out under nitrogen atmosphere and constant stirring at $160^{\circ} \mathrm{C}$ for $1 \mathrm{~h}$. Afterwards, for the second stage of polycondensation, high vacuum (10-3-10-6 Torr), was applied slowly, while the temperature was gradually raised to $180{ }^{\circ} \mathrm{C}$ and left under constant stirring. The final product was obtained the next day after being left at room temperature to solidify.

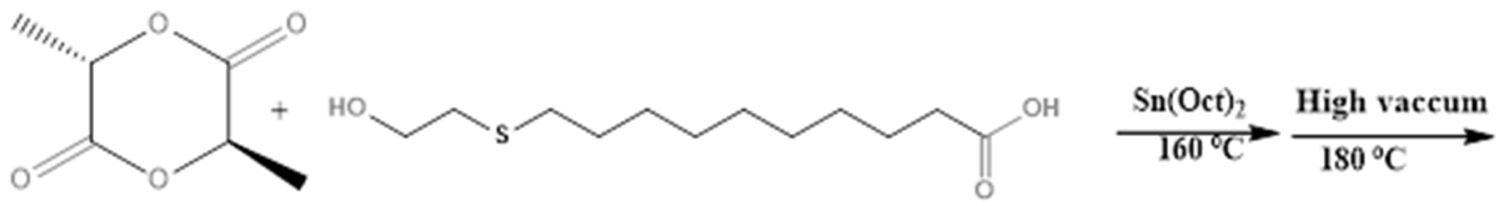
d,I-lactide

TEHA

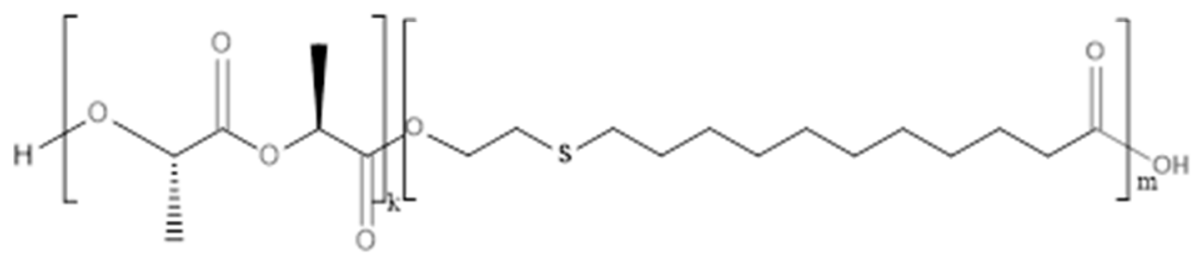

\section{TEHA-CO-PDLLA}

Scheme 3. Synthesis of TEHA-co-PDLA. 
Table 1. Amounts of monomers used to synthesize copolymers with different molecular ratios, expressed in $\mathrm{g}$ and $\mathrm{mmol}$.

\begin{tabular}{|c|c|c|c|c|c|}
\hline \multirow[t]{2}{*}{ C-polymer } & \multicolumn{2}{|c|}{$\begin{array}{c}\text { d,l-lactide } \\
M_{\mathrm{w}} 144,13 \\
\text { g/mol }\end{array}$} & \multicolumn{2}{|c|}{$\begin{array}{c}\text { TEHA } \\
M_{\mathrm{w}} 262.41 \\
\mathrm{~g} / \mathrm{mol}\end{array}$} & \multirow{2}{*}{$\begin{array}{c}\text { TEHA: } \\
\text { d,l-lactide } \\
\text { Molar } \\
\text { Ratio }\end{array}$} \\
\hline & g & mmol & g & mmol & \\
\hline $\begin{array}{c}\text { TEHA-co- PDLLA } \\
1 / 5\end{array}$ & 10 & 69 & 3.64 & 13.9 & $1: 5$ \\
\hline $\begin{array}{c}\text { TEHA-co- PDLLA } \\
1 / 50\end{array}$ & 15 & 104 & 0.55 & 2.1 & $1: 50$ \\
\hline $\begin{array}{c}\text { TEHA-co- PDLLA } \\
1 / 70\end{array}$ & 15 & 104 & 0.39 & 1.5 & $1: 70$ \\
\hline $\begin{array}{c}\text { TEHA-co- PDLLA } \\
1 / 140\end{array}$ & 15 & 104 & 0.20 & 0.7 & 1:140 \\
\hline
\end{tabular}

\section{Discussion}

\subsection{Synthesis}

The addition of mercaptoethanol was carried out to obtain TEHA under UV-irradiation at room temperature in the presence of DMPA as photoinitiator (Scheme 1). The reaction has been previously described to proceed moderately rapidly at temperatures below $100{ }^{\circ} \mathrm{C}$, with the assistance of ultraviolet light. The successful synthesis of TEHA was confirmed using $1 \mathrm{H}-\mathrm{NMR}$ spectroscopy, that showed full conversion of the double bonds by the disappearance of the vinylic and allylic hydrogen signals at 5.35 and $2.00 \mathrm{ppm}$ respectively, shown in Figure 1. In addition to the disappearance of the vinyl and allylic proton signals, new peaks corresponding to the protons linked to the carbon bearing the hydroxyl group at $3.72 \mathrm{ppm}$ (Figure 1, H1), for the protons linked to the carbon bearing the carboxylic group at $2.34 \mathrm{ppm}$ (Figure 1, H4) and for the methylene groups linked to sulfur at 2.73 and $2.51 \mathrm{ppm}$ (Figure 1, H2, H3), were clearly visible in the spectrum of TEHA [11].

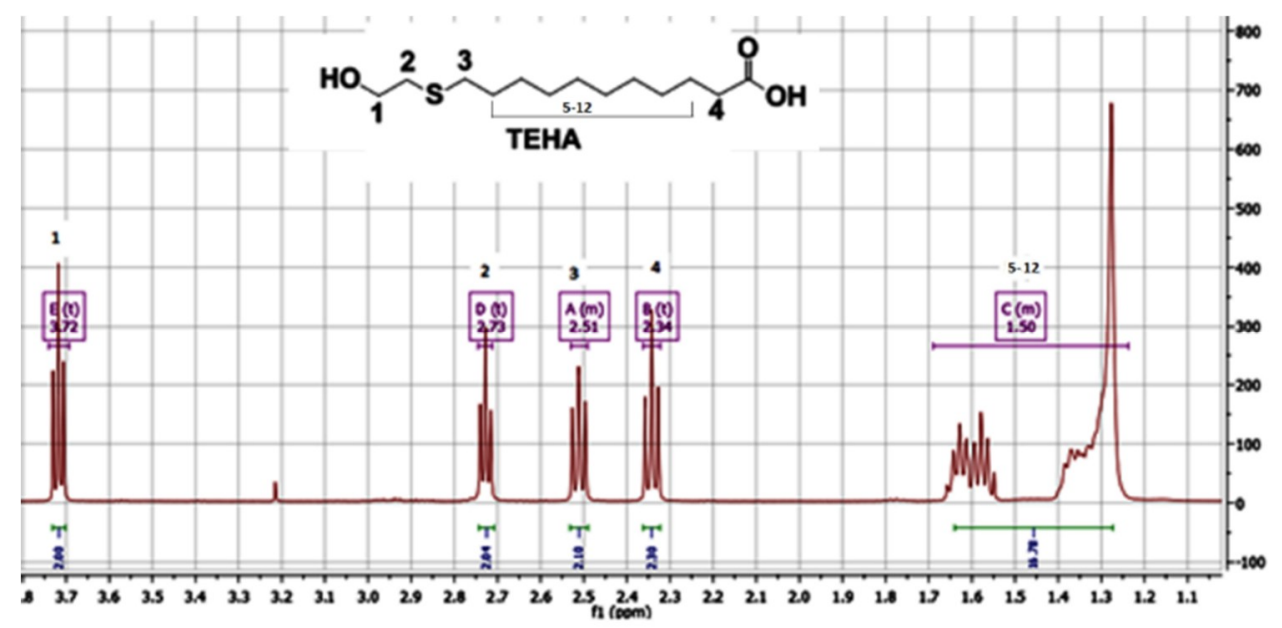

Figure 1. 1 H-NMR spectra of a) TEHA.

Figure 2 shows the 1H-NMR spectra of TEHA-co-PDLLA copolymers, compared to the TEHA di-hydroxy acid spectrum. To all characteristic peaks have been assigned numbers equivalent to the protons of each atom they contribute to. These numbers are the following:

$1 \mathrm{H}-\mathrm{NMR}\left(\mathrm{CDCl}_{3}, \mathrm{~d}, \mathrm{ppm}\right): 5.15(\mathrm{t}, 1 \mathrm{H},-\mathrm{O}-\mathrm{CH}-\mathrm{CO}), 4.32(\mathrm{t}, 1 \mathrm{H}, \mathrm{HO}-\mathrm{CH}-\mathrm{CO}), 4.18\left(\mathrm{t}, 2 \mathrm{H},-\mathrm{CH}_{2}-\right.$ O) -), $2.73\left(\mathrm{t}, 2 \mathrm{H},-\mathrm{CH}_{2}-\mathrm{S}-\right), 2.51\left(\mathrm{~m}, 2 \mathrm{H},-\mathrm{CH}_{2}-\mathrm{S}-\right), 2.34\left(\mathrm{t}, 2 \mathrm{H},-\mathrm{CH}_{2}-\mathrm{CO}\right)$. 
1H-NMR spectroscopy showed full conversion of the thioether functions by the appearance of unique signals for $-\mathrm{CH}_{2}-\mathrm{O}-$ protons at 4.18 . Moreover, peaks at 2.51 and $2.73 \mathrm{ppm}$ are assigned to methylene protons (- $\left.\mathrm{CH}_{2}-\mathrm{S}-\right)$ of TEHA and those at $2.34 \mathrm{ppm}$ correspond to the $-\mathrm{CH}_{2} \mathrm{CO}-$ protons, in PLA and TEHA units.

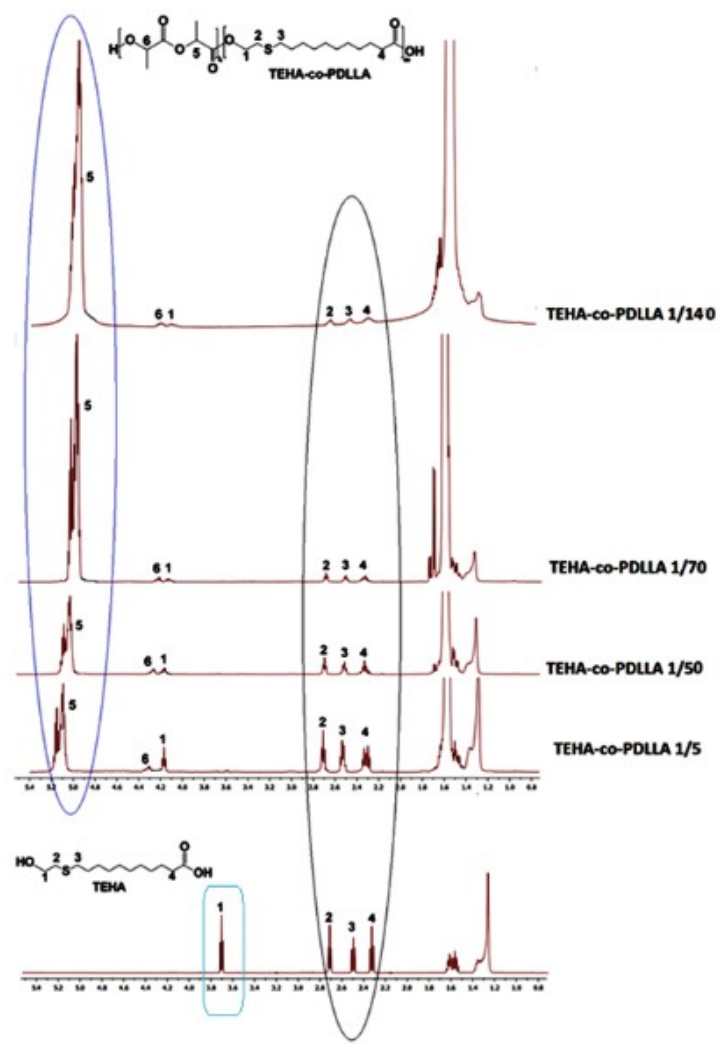

Figure 2. 1H-NMR spectra of TEHA hydroxy acid and TEHA-co-PDLLA copolymer.

In the FTIR spectrum of TEHA-co-PDLA copolymer shown in Figure 3, the absorption attributed to the $-\mathrm{OH}$ group is observed in the range of $3600-3500 \mathrm{~cm}^{-1}$, the asymmetric and symmetric stretching vibration of the $-\mathrm{CH}$ bond at $3000-2850 \mathrm{~cm}^{-1}$. The sharp and intense bands at 1720 and $1100-1000 \mathrm{~cm}^{-1}$ can be assigned to the presence of carboxylic ester $(-\mathrm{C}=\mathrm{O})$ and ether $(\mathrm{C}-\mathrm{O})$ groups, confirming that the synthesis has occurred successfully.

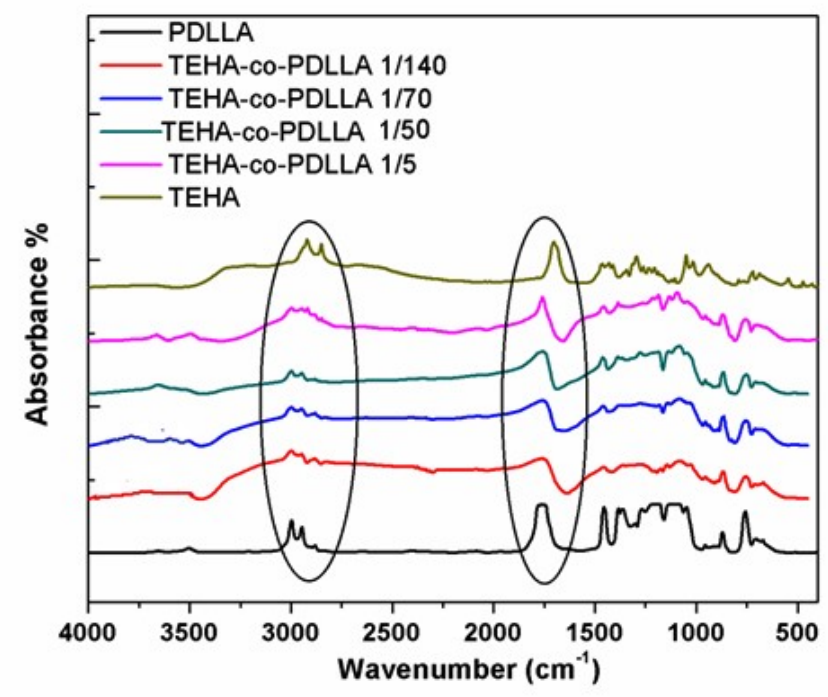

Figure 3. FT-IR spectra of TEHA hydroxy acid and TEHA-co-PDLLA copolymers. 


\subsection{Crystallization Properties}

The crystalline properties of all copolymers were studied by wide angle X-ray. The diffraction pattern of TEHA exhibited four main peaks corresponding to TEHA unit at $2 \theta=21.2^{\circ}, 23.1^{\circ}$, and $24.8^{\circ}$, which confirm the crystalline nature of the dihydroxy acid.

The PDLA diffractogram shows a wide peak from $10^{\circ}$ to $25^{\circ}$ (Figure 4) [12]. Therefore, PDLA is an amorphous polymer that is expected to show a faster hydrolysis rate. The amorphous nature of this polymer is due to its stereoregulation, as it has randomly repeated units of D-lactide and L-lactide in its structure. The absence of TEHA peaks in the diffractograms of TEHA-co-PDLLA copolymers confirms the amorphous nature of the materials. Previously reported studies suggest that because of the amorphous nature of materials, it is usually anticipated that they will have a faster rate of degradation.

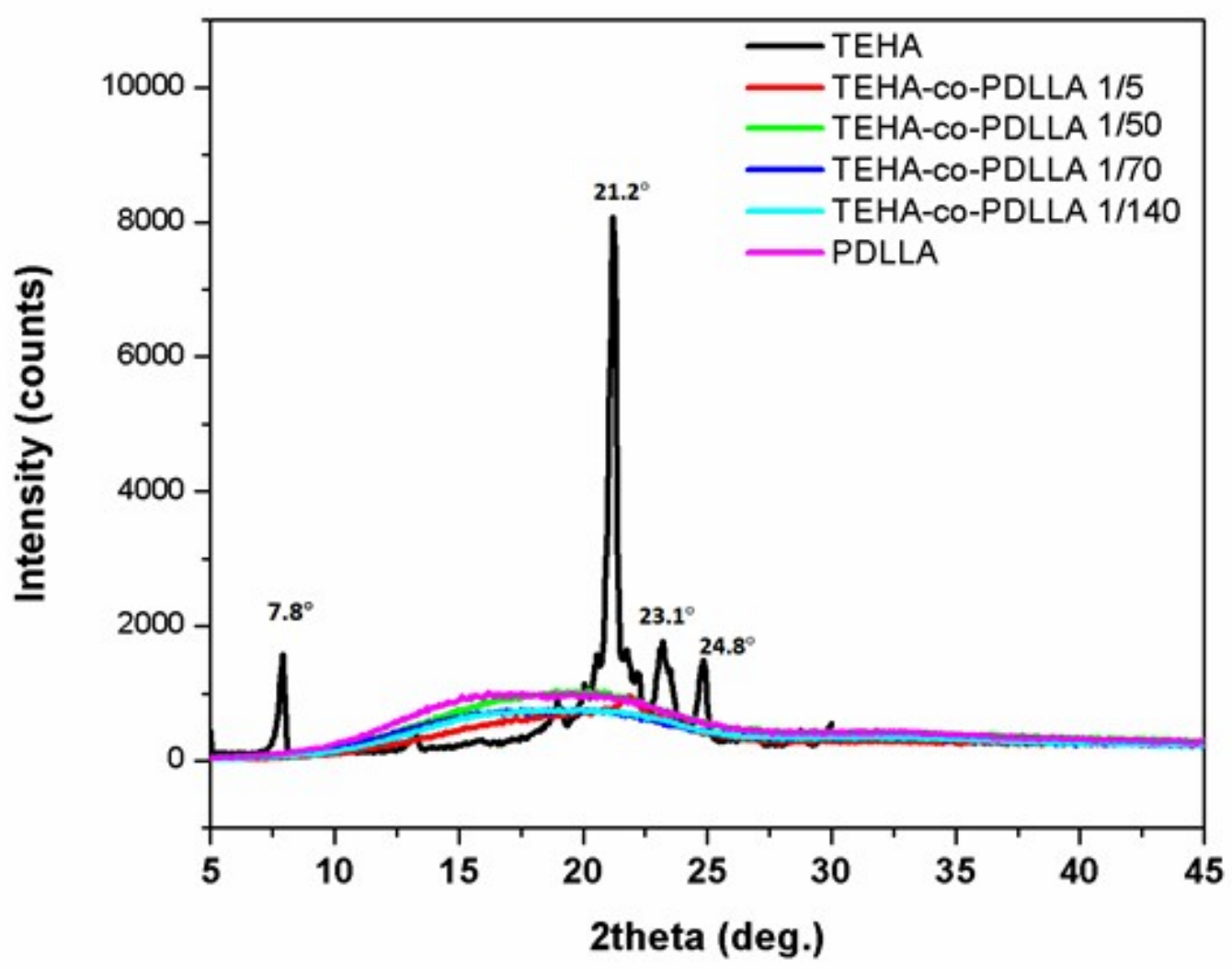

Figure 4. XRD patterns of TEHA, PDLA and TEHA-co-PDLA.

\subsection{Thermal Properties}

The crystalline nature of the TEHA monomer is also confirmed by the study of its thermal properties, with differential scanning calorimetry (DSC). In the present work, all the copolymers were heated from room temperature to $100^{\circ} \mathrm{C}$, cooled from 100 to $20^{\circ} \mathrm{C}$ and reheated at this temperature, in order to produce maximum TEHA block crystallinity. Melting points and enthalpies were then recorded for the second heating cycle.

The melting temperature of TEHA was $T_{\mathrm{m} 2}=71.2^{\circ} \mathrm{C}$, with the corresponding enthalpy of melting $\Delta H_{\mathrm{m} 2}=169.5(\mathrm{~J} / \mathrm{g})$, the crystallization temperature $T_{\mathrm{c}}=52.4^{\circ} \mathrm{C}$ and the crystallization enthalpy $\Delta H_{\mathrm{c}}=$ $-165.7(\mathrm{~J} / \mathrm{g})$.

The glass transition of PDLA homopolymer and TEHA-co-PDLA copolymers was recorded during the second heating of the materials in an expected temperature range, from 30 to $60^{\circ} \mathrm{C}$ (Figure 5). In this particular temperature range, the mobility of the polymer chains at the glass transition temperature, $T_{\mathrm{g}}$, increases sharply. 


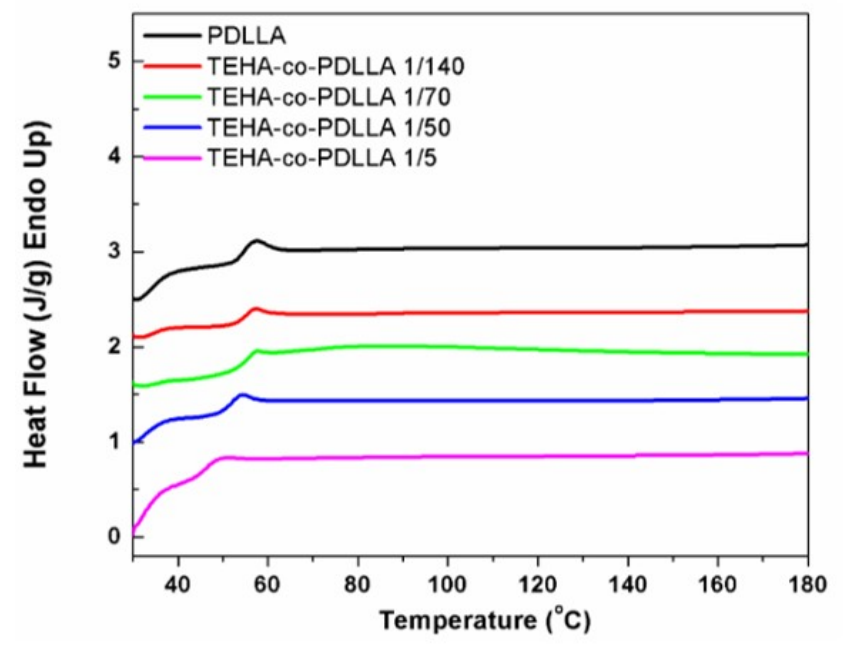

\begin{tabular}{|c|c|}
\hline Sample & $\begin{array}{l}T_{\mathrm{g}}^{\mathrm{a}} \\
\left({ }^{\circ} \mathrm{C}\right)\end{array}$ \\
\hline PDLLA & 54.5 \\
\hline $\begin{array}{l}\text { TEHA-co- PDLLA } \\
1 / 140\end{array}$ & 53.8 \\
\hline TEHA-co- PDLLA 1/70 & 53.5 \\
\hline TEHA-co- PDLLA 1/50 & 50.9 \\
\hline TEHA-co- PDLLA 1/5 & 44.7 \\
\hline
\end{tabular}

Figure 5. DSC scan results for PDLA and TEHA-co-PDLA copolymers.

In Figure 5, it is clear that as the molar ratio of TEHA increases, the $T_{8}$ of TEHA-co-PDLLA copolymers gradually decreases. Since the value of the $T_{g}$ depends on the molecular characteristics that affect the relative stiffness of the chains, it can be concluded that the presence of TEHA building blocks facilitates the mobility of PDLLA macromolecular chains in the TEHA-co-PDLA copolymers, and therefore reduces the $T_{g}$. Based on these observations, it seems that TEHA acts as a plasticizer for PDLLA.

\section{Conclusions}

The thiol-ene Michael addition of mercaptoethanol to the double bonds of methyl 10-undecenoic acid leads to excellent yields and the thus obtained monomer TEHA, which was copolymerized with PLA. It can be concluded that these new copolymers may be appropriate for biological and drug delivery applications.

Acknowledgments: This research has been co-funded by the European Regional Development Fund (ERDF) and from national resources through the Operational Program "Competitiveness, Entrepreneurship and Innovation", NSFR 2014-2020, under the call "Aquaculture"-"Industrial materials"-"Open innovation in culture" ( project code: Т6ҮBП-00288).

\section{References}

1 B.S. Kim, Y.W. Kwon, J.S. Kong, G.T. Park, G. Gao, W. Han, M.B. Kim, H. Lee, J.H. Kim, D.W. Cho, 3D cell printing of in vitro stabilized skin model and in vivo pre-vascularized skin patch using tissue-specific extracellular matrix bioink: A step towards advanced skin tissue engineering, Biomaterials. 2018, 168, 3853. https://doi.org/10.1016/j.biomaterials.2018.03.040.

2 X. Zhao, H. Wu, B. Guo, R. Dong, Y. Qiu, P.X. Ma, Antibacterial anti-oxidant electroactive injectable hydrogel as self-healing wound dressing with hemostasis and adhesiveness for cutaneous wound healing, Biomaterials. 2017, 122, 34-47. https://doi.org/10.1016/j.biomaterials.2017.01.011.

3 F. Hafezi, N. Scoutaris, D. Douroumis, J. Boateng, 3D printed chitosan dressing crosslinked with genipin for potential healing of chronic wounds, Int. J. Pharm. 2019, 560, 406-415. https://doi.org/10.1016/j.ijpharm.2019.02.020.

4 N. Cubo, M. Garcia, J.F. Del Cañizo, D. Velasco, J.L. Jorcano, 3D bioprinting of functional human skin: Production and in vivo analysis, Biofabrication. 2017, 9. https://doi.org/10.1088/1758-5090/9/1/015006.

5 S. Saghazadeh, C. Rinoldi, M. Schot, S.S. Kashaf, F. Sharifi, E. Jalilian, K. Nuutila, G. Giatsidis, P. Mostafalu, H. Derakhshandeh, K. Yue, W. Swieszkowski, A. Memic, A. Tamayol, A. Khademhosseini, Drug delivery systems and materials for wound healing applications, Adv. Drug Deliv. Rev. 2018, 127, 138-166. https://doi.org/10.1016/j.addr.2018.04.008. 
6 J. Long, A.E. Etxeberria, A. V. Nand, C.R. Bunt, S. Ray, A. Seyfoddin, A 3D printed chitosan-pectin hydrogel wound dressing for lidocaine hydrochloride delivery, Mater. Sci. Eng. C. 2019, 104, 109873. https://doi.org/10.1016/j.msec.2019.109873.

7 A.P. Gupta, V. Kumar, New emerging trends in synthetic biodegradable polymers - Polylactide: A critique, Eur. Polym. J. 2007, 43, 4053-4074. https://doi.org/10.1016/j.eurpolymj.2007.06.045.

8 C.L. Sungyeap Hong, An Overview of the Synthesis and Synthetic Mechanism of Poly (Lactic acid), Mod. Chem. Appl. 2014, 02. https://doi.org/10.4172/2329-6798.1000144.

9 O. Türünç, M.A.R. Meier, Fatty acid derived monomers and related polymers via thiol-ene (Click) additions, Macromol. Rapid Commun. 2010, 31, 1822-1826. https://doi.org/10.1002/marc.201000291.

10 C. Jérôme, P. Lecomte, Recent advances in the synthesis of aliphatic polyesters by ring-opening polymerization, Adv. Drug Deliv. Rev. 2008, 60, 1056-1076. https://doi.org/10.1016/j.addr.2008.02.008.

11 M. Nerantzaki, K.V. Adam, I. Koliakou, E. Skoufa, A. Avgeropoulos, G.Z. Papageorgiou, D. Bikiaris, Novel Castor Oil-Derived Block Copolymers as Promising Candidates for Biological Applications: Biorelevant and Biocompatible, Macromol. Chem. Phys. 2017, 218, 1-13. https://doi.org/10.1002/macp.201700305.

12 J.R. Sarasua, E. Zuza, N. Imaz, E. Meaurio, Crystallinity and crystalline confinement of the amorphous phase in polylactides, Macromol. Symp. 2008, 272, 81-86. https://doi.org/10.1002/masy.200851211.

Publisher's Note: MDPI stays neutral with regard to jurisdictional claims in published maps and institutional affiliations.

(C) 2020 by the authors. Submitted for possible open access publication under the terms and conditions of the Creative Commons Attribution (CC BY) license (http://creativecommons.org/licenses/by/4.0/). 